\title{
Degradation of 2,4,6-trinitrotoluene by $P$. aeruginosa and characterization of some metabolites
}

\author{
Hatice Aysun Mercimek ${ }^{1}$, Sadik Dincer ${ }^{2}$, Gulcihan Guzeldag ${ }^{1}$, Aysenur Ozsavli ${ }^{1}$, \\ Fatih Matyar ${ }^{3}$, Afet Arkut ${ }^{4}$, Fikret Kayis ${ }^{2}$, Melis Sumengen Ozdenefe ${ }^{2}$ \\ ${ }^{1}$ Department of Molecular Biology and Genetics, Kilis 7 Aralik University, Kilis, Turkey. \\ ${ }^{2}$ Department of Biology, Cukurova University, Adana, Turkey. \\ ${ }^{3}$ Department of Science and Technology Education, Cukurova University, Adana, Turkey. \\ ${ }^{4}$ Department of Nutrition and Dietetics, Faculty of Health Sciences, Cyprus International University, \\ Nicosia, Turkey.
}

Submitted: January 13, 2014; Approved: June 6, 2014.

\begin{abstract}
Degradation of 2,4,6-trinitrotoluene (TNT), a nitroaromatic explosive found in the soil and ground water, was investigated using Pseudomonas aeruginosa in in vitro experiments. Biodegradable abilitiy of this bacteria was performed with 50 and $75 \mathrm{mg} \mathrm{L}^{-1} \mathrm{TNT}$ concentrations in a defined liquid medium for $96 \mathrm{~h}$ time period. Treatment of TNT in supernatant samples taken at 0, 6, 12, 24, 48, 72 and $96 \mathrm{~h}$ from agitated vessels was followed by reverse-phase high-performance liquid chromatography (HPLC). In cultures supplemented with 50 and $75 \mathrm{mgL}^{-1} \mathrm{TNT}$, after $96 \mathrm{~h}$ of incubation $46 \%$ and $59 \%$ reduction were detected respectively. Two metabolites as degradation intermediates with nitrite release into the medium, 2,4-dinitrotoluene (2,4-DNT) and 4-aminodinitrotoluene (4-ADNT), were elucidated by thin layer chromatography (TLC) and gas chromatography-mass spectrometry (GCMS). These findings clearly indicate that Pseudomonas aeruginosa can be used in bioremediation of TNT contaminated sites.
\end{abstract}

Key words: Pseudomonas sp, biotransformation, nitroaromatic explosives, TNT.

\section{Introduction}

Oligonitroaromatic compounds are well-known environmental pollutants which are used in many industrial processes, including the production of pesticides, dyes, polymers, plastics, herbicides, explosives, textile, paper and pharmaceuticals (Ju and Parales, 2010). These pollutants over several decades have leaked to soils, groundwaters, surfacewaters and wastewaters around manufacturing sites as a result of their release in industrial effluents (Robertson ve Jjemba, 2005; Kalderis et al., 2008; Lotufo et al., 2010).

2,4,6-trinitrotoluene is a nitroaromatic explosive which has been extensively used for military purposes due to its low melting point, chemical and thermal stability, low sensitivity to impact and friction (Park et al., 2002; Robertson ve Jjemba, 2005; Kalderis et al., 2008; Lin et al., 2013). It was reported that its production reached a maximum dur- ing World War II (Zheng et al., 2009; Ayoub et al., 2010; Zhang et al., 2011). Toxic and mutagenic effects of TNT to various organisms ranging from microorganisms and humans have been described even at low concentration (its lethal dose 0.8-13 g/kg) (Seth-Smith 2002; Dodard et al., 2004; Ayoub et al., 2010). TNT as possible human carcinogenic (class C) has been classified by United States Environmental Protection Agency (Gandia-Herrero et al., 2008) and also refered to cause diseases such as rashes, toxic hepatitis, dermatitis, cyanosis, sneezing, cough, peripheral neuritis, cataract, muscular pain, aplastic anemia and kidney damage when exposure to it (Kalderis et al., 2008; Yang et al., 2008).

Owing to these impacts, improving the effective technology for remediation of TNT-polluted sites is immediately needed (Fleischmann et al., 2004). Until today, several methods for treating of TNT contamined site have 
been developed, including incineration, compositing, chemical oxidation and adsorption (Baretto-Rodrigues et al., 2009; Wang et al., 2010) Limitations containing the retention of untreated and undefinied compounds, costliness, the requirement of additional nutrients and incomplete degradation of TNT, recent researches have caused to focus on biotreatment processes which are an efficient, cost effective and environmental friendly (Fu et al., 2012).

This hazardous chemical which is persistent to degradation in environmental, is sensitivity to microbial attack. Evidences of TNT transformation by aerobic, anaerobic and combined processes are available in the literature (Robertson and Jjemba, 2005; Moshe et al., 2009; Montgomery et al., 2013). The present paper aims to investigate the transformation capacity of TNT to non-toxic byproduct by Pseudomonas aeruginosa which was isolated from soil.

\section{Materials and Methods}

\section{Isolation of Pseudomonas}

For isolation of microorganism, soil sample was collected from the NATO military industry region, Izmir, Turkey. $1 \mathrm{~g}$ of soil sample in $99 \mathrm{~mL}$ of Glutamate Starch Phenol Red (GSP) medium (Coral and Karagoz 2005) containing the following $\left(\mathrm{g} \mathrm{L}^{-1}\right.$ distilled water) sodium $\mathrm{L}(+)$ glutamate (10), soluble starch (3.5), $\mathrm{KH}_{2} \mathrm{PO}_{4}$ (2), $\mathrm{MgSO}_{4} .7 \mathrm{H}_{2} \mathrm{O}(0.5)$, phenol red (0.36), was incubated on an orbital shaker (180 rpm as aeration speed) at $30^{\circ} \mathrm{C}$ for $72 \mathrm{~h}$. And then $100 \mu \mathrm{L}$ of growth culture was transferred to an GSP agar plate for preliminary isolation. The plate was incubated at $30^{\circ} \mathrm{C}$ for $72 \mathrm{~h}$ under aerobically conditions. After incubation the selected colonies which were $2-3 \mathrm{~mm}$ in diameter, red and red-zone around theirs on plate, were maintained on an Nutrient agar slant. Isolates tested by Gram staining and biochemical tests were defined using VITEK bacterial identification system.

\section{Evaluation of tolerance}

Tolerance of the isolated strains to TNT was analysed by growing in an aqueous medium contained different concentrations of TNT $\left(5,10,15,30,50,75\right.$ and $\left.100 \mathrm{mg} \mathrm{L}^{-1}\right)$. This degradation medium which consisted of $\left(\mathrm{g} \mathrm{L}^{-1}\right)$ $\mathrm{K}_{2} \mathrm{HPO}_{4}, 6.18 ; \mathrm{KH}_{2} \mathrm{PO}_{4}, 1.93$; yeast extract, $1 ; \mathrm{pH}$ adjusted to 7.2 using $1 \mathrm{~N} \mathrm{NaOH}$, was prepared by adding from the stock solution of TNT prepared in acetone $\left(1000 \mathrm{mg} \mathrm{L}^{-1}\right)$ was filtered through $(0.22 \mu \mathrm{m})$ sterilized (Tope et al., 1999).

\section{Bioremediation}

The capability of the selected isolate to remove TNT was investigated by two processes: (i) Preproduction: The isolate was grown in liquid medium including $\left(\mathrm{g} \mathrm{L}^{-1}\right)$ meat extract, 10 ; meat peptone, $10 ; \mathrm{NaCl}, 5 ; \mathrm{K}_{2} \mathrm{HPO}_{4}, 2$; $\mathrm{KH}_{2} \mathrm{PO}_{4}, 1 ; \mathrm{MgSO}_{4} .7 \mathrm{H}_{2} \mathrm{O}, 0.2 ; \mathrm{pH} 7.2$, (Tope et al., 1999) at $30^{\circ} \mathrm{C}$ with shaking $(180 \mathrm{rpm})$ for $24 \mathrm{~h}$. After incubation, separated cells by centrifugated $\left(9000 \mathrm{x} g\right.$ for $\left.10 \mathrm{~min}+4^{\circ} \mathrm{C}\right)$ were washed twice with $50 \mathrm{mM}$ potasium phosphate buffer $(\mathrm{pH} 7.3)$. A final optical density $\left(\mathrm{OD}_{600}\right)$ of acquired bacterial suspension was adjusted about 4.8 and $50 \mathrm{~mL}$ of this biomass was evaluated as inoculum culture for second process. (ii) Incubation of inoculums in different TNT concentaration (50 and $75 \mathrm{mg} \mathrm{L}^{-1}$ ) containing degradation medium and monitoring of bacterial growth: In shaking flask, the biomass was grown at $30 \hat{\mathrm{A}}^{\circ} \mathrm{C}(180 \mathrm{rpm})$ in the dark for $96 \mathrm{~h}$. Throughout the experiment, the growth was followed by recording the absorbance at $600 \mathrm{~nm}$ and counting viable colonies on plate count agar (PCA). Uninoculated flasks were utilized as controls, as well as flasks containing the bacteria without TNT.

\section{Following TNT transformation}

\section{Extraction}

To identify the major intermediates of TNT by Pseudomonas aeruginosa, $50 \mathrm{~mL}$ of bacterial cultures and control groups were sacrificed at each time point $(0,6,12,24$, 48,72 and $96 \mathrm{~h}$ ), centrifuged at $9000 \mathrm{x} g$ for $1 \mathrm{~h}$ at $4{ }^{\circ} \mathrm{C}$. The acidified culture supernatants $(20 \mathrm{~mL})$ with $1 \mathrm{~N} \mathrm{HCl}$ $160 \mu \mathrm{L}$ for per $1 \mathrm{~mL}$ sample, were extracted twice with equal volume of ethyl acetate. After acidification, $\mathrm{H}_{2} \mathrm{O}$ was removed from the extracts over anhydrous $\mathrm{Na}_{2} \mathrm{SO}_{4}$. And then the extracts were concentrated by removing excess solvent with rotary evaporation at $35^{\circ} \mathrm{C}$. The reconstituted residues in $1 \mathrm{~mL}$ of acetonitrile, were preserved at $+4{ }^{\circ} \mathrm{C}$ in $1.5 \mathrm{~mL}$ teflon coated brownglass vial for HPLC, GC MS and TLC analysis (Schackmann and Müller 1991).

\section{Analysis of TNT}

Analysis of TNT transformation was carried out using a Schimadzu, Japan HPLC equipped with a UV detector at $254 \mathrm{~nm}$. Chromatographic separation was performed by injected a sample volume of $20 \mu \mathrm{L}$ into a $\mathrm{C} 18$ reverse phase column at $30{ }^{\circ} \mathrm{C}$. The mobile phase comprised of $21 \%(\mathrm{v} / \mathrm{v})$ acetonitrile; $35 \%$ methanol and $44 \%$ deionized water. This phase mixture was isocratically delivered to column at a

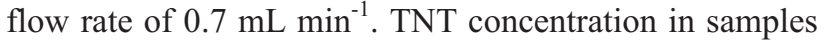
was determined by comprasion a peak height that yielded with reference standarts (Mercimek et al., 2013).

\section{Identification of degradation products by TLC and GC MS analyses}

Final confirmation of target products made whereby GC/MS and TLC. In GC/MS analyses, TNT intermadiates were identified by comparison of retentions times and mass spectra between samples and standart chemicals. The samples were chromatographed with a gradient temprature programme using TR5-MS column ( $60 \mathrm{mx} 0.25 \mathrm{~mm}, 0.25 \mu \mathrm{m}$ film thickness) and ionization detector. Initial oven temperature $80{ }^{\circ} \mathrm{C}$ for $1 \mathrm{~min}$ was ramped to $300{ }^{\circ} \mathrm{C}$ with a rise $10^{\circ} \mathrm{C} \mathrm{min}{ }^{-1}$ and held for $12 \mathrm{~min}$ final hold. The injector 
temperature was $240{ }^{\circ} \mathrm{C}$. Helium flow rate was adjusted at $1 \mathrm{~mL} \mathrm{m^{-1 }}$ and the injection volume was $1 \mu \mathrm{L}$ (Oh and Kim, 1998; Mercimek et al., 2013).

In TLC analyses, the metabolic products were separated by the ascending method with a solvent system consisting of ethyl acetate/hexan $(40: 60 \mathrm{v} / \mathrm{v})$ on pre-coated plates of silica gel F254 purchased from Merck (Nam 1997). For identifiaction of spots indicating TNT metabolits, TLC sheets were visualized under UV illumination. $\mathrm{Rf}$ values of the spots were determined by comparing those of the authentic standards.

\section{Other analyses}

During the degradation, demineralization of TNT that is responsible for nitrite ion release was analyzed by spectrophotometrically (Nyanhongo et al., 2006). From $20 \mathrm{~mL}$ of the cultures withdrawn, was centrifuged at $9000 \mathrm{xg}$ for $1 \mathrm{~h}$. The acquired supernatant $(200 \mu \mathrm{L})$ was transfered to test tubes including $50 \mu \mathrm{L}$ sulphanilamide solution which was prepared by dissolving $5 \mathrm{~g}$ sulphanilamide in $26 \mathrm{~mL}$ $\mathrm{HCl}$ and adjusting total volume of solution to $500 \mathrm{~mL}$ in distilled water. After incubation at room temperature for 5 min, $50 \mu \mathrm{L} \mathrm{N}$-(1-naphthly) ethylenediamine dihydrochloride solution $(0.5 \mathrm{~g} \mathrm{~N}$-(1-naphthyl) ethylenediamine dihydrochloride in $500 \mathrm{~mL}$ deoinized water) as the coloring reagent was added to reaction mixture and incubated for $20 \mathrm{~min}$ at room temperature. Total volume of reaction mixture was adjusted at $1 \mathrm{~mL}$ with deoinized water and nitrite concentration was determined the OD at $540 \mathrm{~nm}$. The oxidation of released nitrite to nitrate was followed by mixing $5 \mathrm{~mL}$ of supernatant with $1 \mathrm{~mL} 1 \mathrm{~N} \mathrm{HCl}$ and then examining at $220 \mathrm{~nm}$ (Al-Absi 2008).

\section{Results}

\section{Isolation and identification of the Pseudomonas sp}

In NATO soil sample, bacterial population that is capability of growth in the presence of TNT, was screened on GSP agar. This medium contains glutamate and strach as its sole nutrients. While many microorganisms can not metabolize these compounds, Aeromonas was able to hydrolyze with acid production the starch, causing phenol red to change yellow but not by Pseudomonas. These bacteria formed a red precipitation zone surronding colonies, 2-3 mm in diameter, on GSP agar plates. All of the selected strains were revealed belonging to the Pseudomonas genus, with possible similarities such as Gram negative, bacillishaped, oxidase and citrate positive. It was finally defined that isolated ten strains were Pseudomonas sp. by VITEK bacterial identification system.

\section{Selection of Pseudomonas sp that used in TNT transformation}

It was observed that only one of the ten isolates was capable to grow in an aqueous medium contained 50 and $75 \mathrm{mg} \mathrm{L}^{-1}$ TNT concentrations. So, this isolate, Pseudomonas aeruginosa, was selected to be used for further degradation studies.

\section{Growth of $P$. aeuroginosa and biodegradation of TNT as sole carbon source}

$P$. aeuroginosa was inoculated in liquid mediums contaning 50 and $75 \mathrm{mg} \mathrm{L}^{-1} \mathrm{TNT}$, to evaluate its capability to utilization of TNT as carbon source by aerobic pathway. It was observed that color of culture mediums that were treated by $P$. aeuroginosa, turned to red color from yellow during degradation. Within 4 days of culturing, degradation efficiency for different concentrations (50 and $75 \mathrm{mg} \mathrm{L}^{-1}$ )

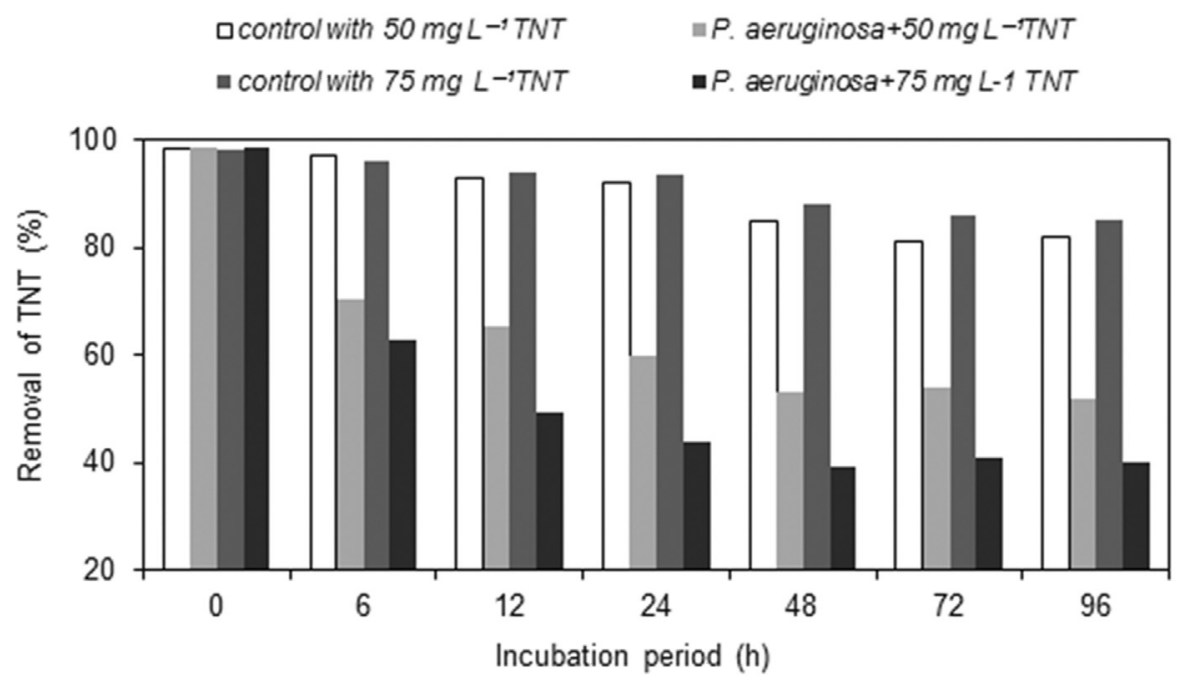

Figure 1 - Degradation of TNT by cell suspensions of $P$. aeruginosa. 
of TNT, was recorded as $46 \%$ and 59\% respectively (Figure 1).

The role of abiotic processes on biotransformation of TNT, was also examined in the uninoculated controls. In these control cultures, at initial concentrations of TNT were determined a decline with time by HPLC (Figure 1). The certain microbial degradation of TNT by $P$. aeuroginosa was calculated by expulsion values of chemical hydrolysis.

During incubation, correlation between decreasing TNT concentrations and increasing density of cells in cultures was followed to prove that $P$. aeuroginosa used TNT as nutritional source. Time-dependent changes in microbial growth (turbidity and colony-froming units (CFU)) were reported in Figure 2. Bacterial growth based on the initial inoculum that was about $102.5 \times 10^{5} \mathrm{cfu} \mathrm{mL}^{-1}$, arose following degradation and reached maximum levels at $12 \mathrm{~h}$ $\left(178 \times 10^{5} \mathrm{cfu} \mathrm{mL} \mathrm{mL}^{-1}\right)$ and $24 \mathrm{~h}\left(208.5 \times 10^{5} \mathrm{cfu} \mathrm{mL}^{-1}\right)$ of incubation in liquid cultures including respectively 50 and $75 \mathrm{mg} \mathrm{L}^{-1}$ TNT (Figure 2a). From that period to by the end of incubation, it was determined that bacterial growth in both concentrations decreased gradually (Figure 2a-b). But biotransformation was shown to proceed with the residual viable cells. In control cultures without TNT, maximum growth was recorded as $131 \times 10^{5} \mathrm{cfu} \mathrm{mL}^{-1}$ at $48 \mathrm{~h}$ (Figure $2 \mathrm{a})$.

\section{Estimation of nitrite and nitrate from TNT}

During degradation time, nitrite analysis was continued to determine the accumulation of nitrite from TNT, as a positive evidence of demineralization and degradation. The findings of nitrite analyses were graphically demonstrated in Figure 3. In bacterial cultures containing $50 \mathrm{mg} \mathrm{L}^{-1} \mathrm{TNT}$, the increase in measurable nitrite concentrations after incubating for $6 \mathrm{~h}$, continued up to $48 \mathrm{~h}$, reached a maximum of $0.28 \mathrm{mg} \mathrm{L}^{-1}$, at $72 \mathrm{~h}$. This value showed the negligible decrease $\left(0.01 \mathrm{mg} \mathrm{L}^{-1}\right)$ and thereafter it remained constant level at $0.27 \mathrm{mg} \mathrm{L}^{-1}$. During the biotransformation, the nitrite amounts in biotic cultures with $75 \mathrm{mg} \mathrm{L}^{-1} \mathrm{TNT}$ showed a gradual rise and the highest nitrite concentration released from TNT was defined $0.47 \mathrm{mg} \mathrm{L}^{-1}$ at $72 \mathrm{~h}$.

In uninoculated media including TNT, nitrite accumulation was observed depending upon the chemical degradation. At the end of $96 \mathrm{~h}$ when was arrived maximum biotransformation, amount of nitrite that measured for both of abiotic cultures was $0.15 \mathrm{mg} \mathrm{L}^{-1}$. A significant result with regard to forming nitrate was not achieved. The results of nitrate assays are presented in Figure 4.

\section{The conversion of TNT to reduction products}

In all of the experiments conducted, removal of TNT was associated to an accumulation the possible degradation products. These products in biotic and abiotic cultures
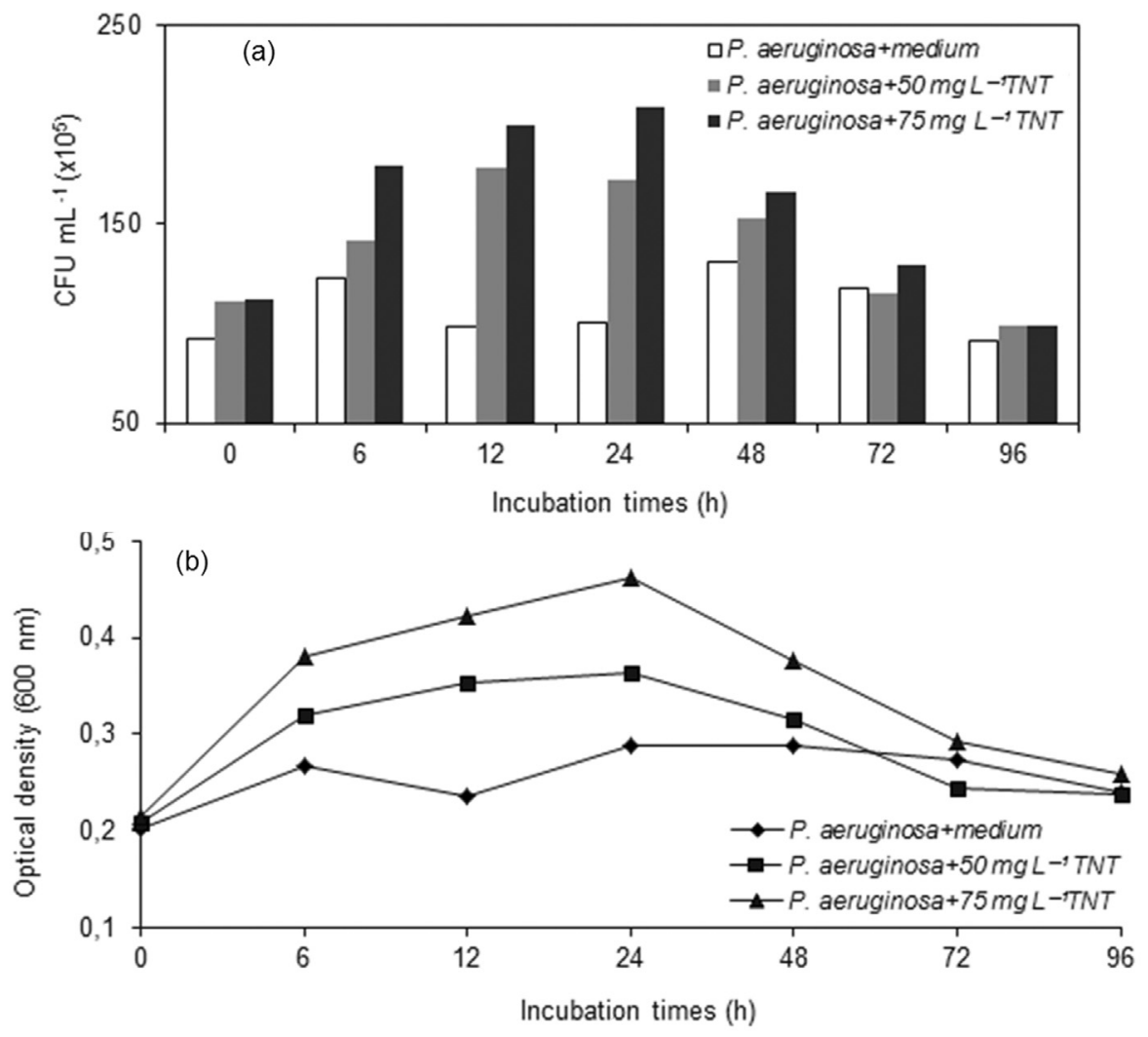

Figure 2 - Changes in bacterial growth following incubation period; (a) viable bacterial counts (cfu $\mathrm{mL}^{-1}$ ) and (b) turbidity of culture mediums with and without TNT inoculated $P$. aeruginosa. 


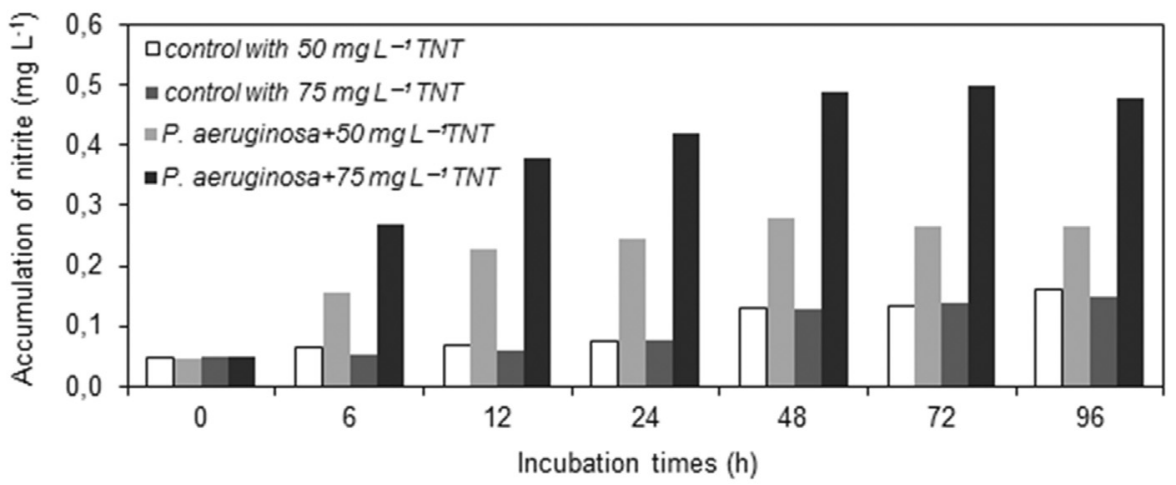

Figure 3 - Release of nitrite during TNT removal by $P$. aeruginosa.

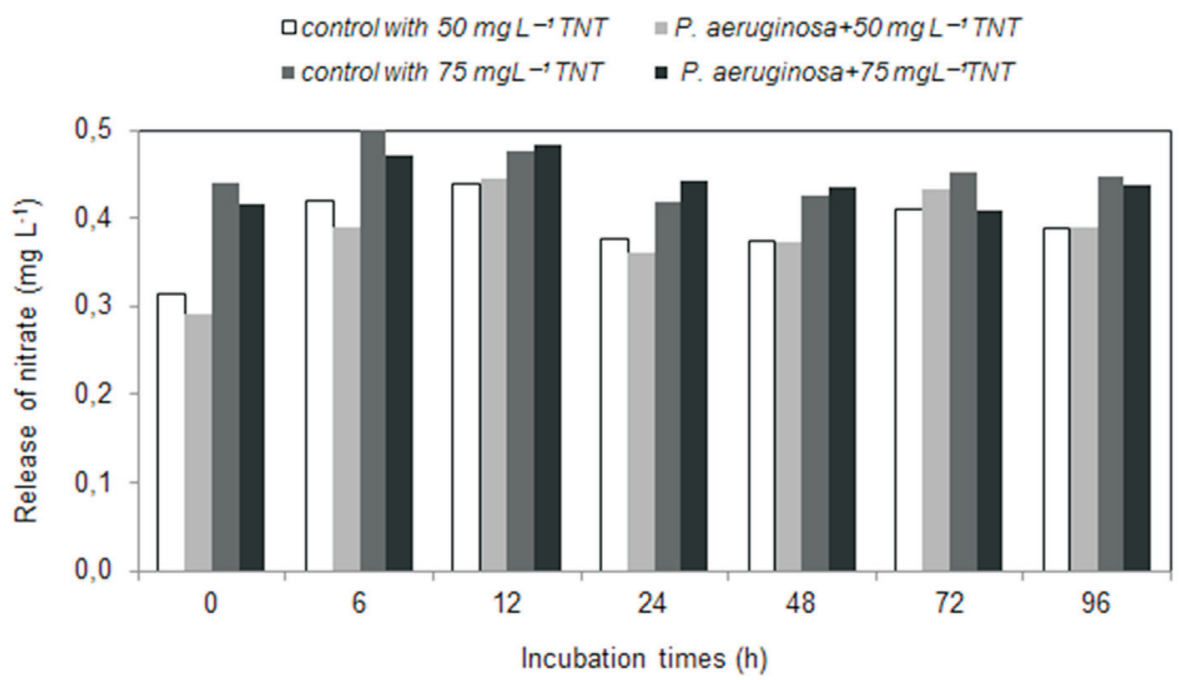

Figure 4 - Detection of nitrate by forming via nitrite reduction.

supernatans were decomposed by GC-MS and preparative TLC plates. The assignment of TNT and its metabolits were based on the match with standart mass spectrum in the GC-MS library database. The retention times of TNT, 2,4DNT and 4-ADNT standarts based on mass/charge were detected as 17.54, 15.65 and $20.14 \mathrm{~min}$, respectively (Figure 5a). From degraded samples of TNT, retention times of peaks at 20.13 and 20.69 min were identified as 4-ADNT by comprasion of standarts (Figure $5 b-c$ ). The metabolite containing amino group (aminodinitrotoluenes) could only be determined in the biotic culture supernatants by GC-MS.

TLC analyses were performed to monitor the removal of TNT and formation of its intermediates. TNT, 2,4-DNT and 4-ADNT standarts migrated with Rf values $0.83,0.67$ and 0.5 (Figure 6a). At the end of degradation, it was revealed the presence two spots on TLC plates, corresponding to the spots belonging to the standarts (Figure 6b-c). These spots at Rf values 0.8 and 0.63 were accepted as TNT and 2,4-DNT. 2,4-DNT couldn't be encountered in the un-inoculated media.

\section{Discussion}

In our experience, it was researched the possibility that TNT degradation by Pseudomonas aeruginosa strain, carried out in liquid medium. In the presence of $P$. aeruginosa, maximum specific removal rates for cultures including 50 and $75 \mathrm{mg} \mathrm{L}^{-1}$ TNT were calculated as $46 \%$ and $59 \%$ within $96 \mathrm{~h}$, respectively. These differences among experiments in the degradation efficiency were mainly related to differences in initial TNT concentrations. Similarly, some workers were published that $P$. aeruginosa and other Pseudomonas sp were ability to grow in the presence of TNT and transform it (Alvarez et al., 1995; Tope and Jamil, 2000; Park et al., 2003; Zaripov et al., 2004; Maeda et al., 2006; Kubota et al., 2008; Nyanhongo et al., 2009). Accordingly our results, chemical hydrolysis of TNT based on agitating in the present studies, was also reported (Oh et al., 2003; Claus et al., 2007).

Generally, we observed that TNT metabolism was correlated with the increasing in microbial growth of $P$. aeruginosa accompanied by decrasing of TNT amounts in the cultures. 

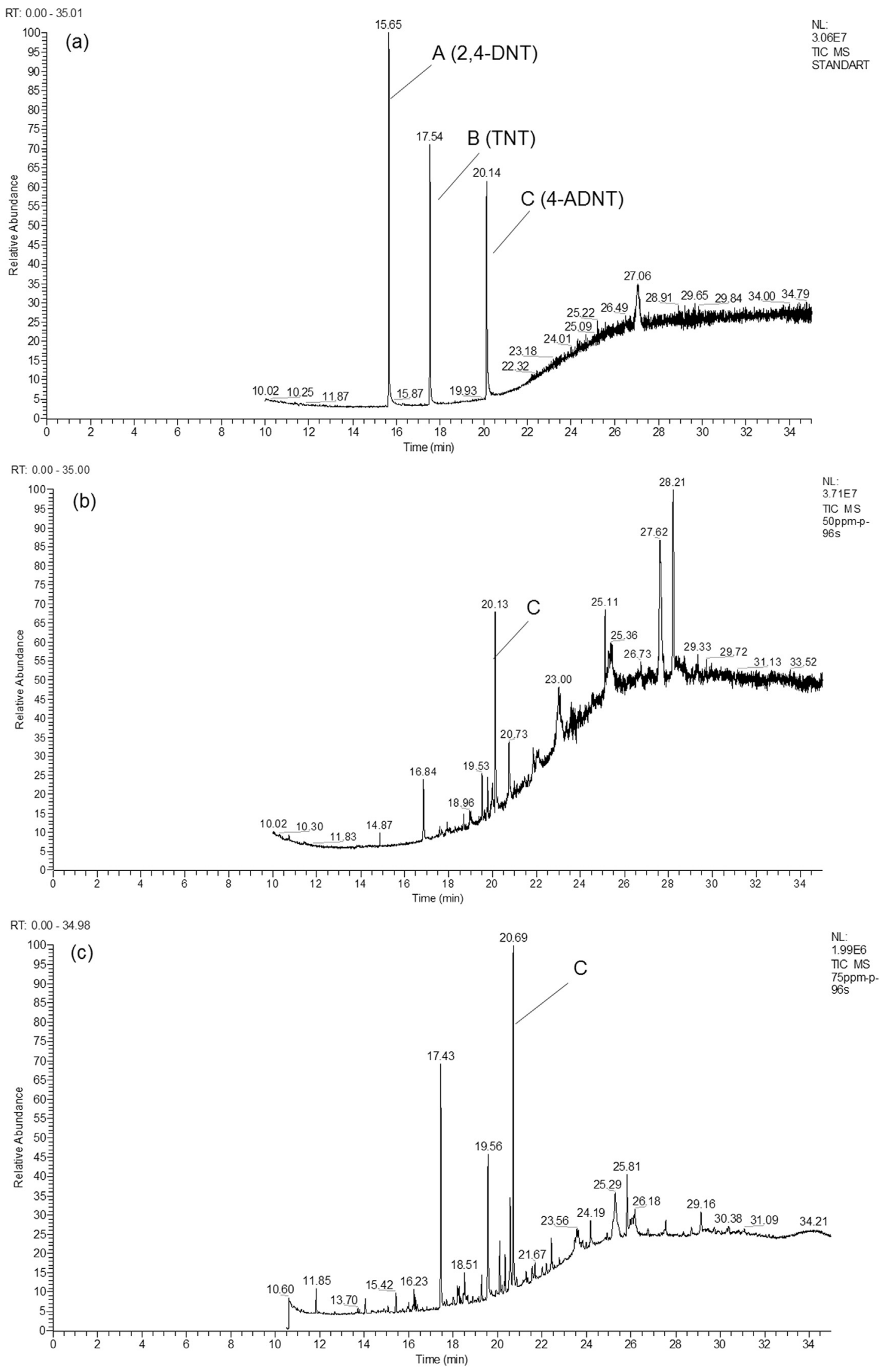

Figure 5 - GC-MS spectra of peaks belonging to analytical standarts (a) and samples obtained from cultures contaning respectively 50 (b) and 75 (c) $\mathrm{mg} \mathrm{L}^{-1}$ TNT. 

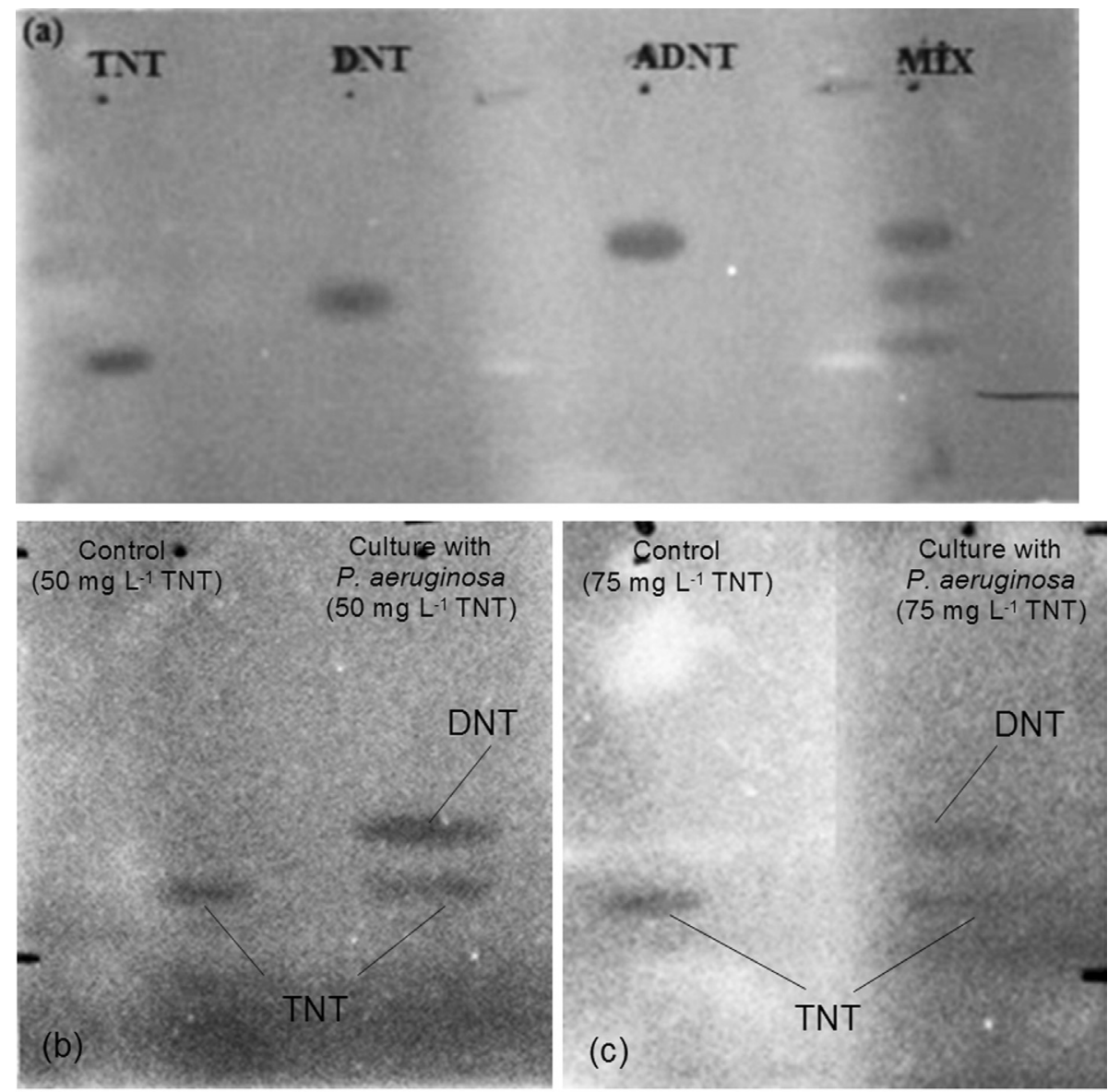

Figure 6 - TLC monitoring of intermediates formed during transformation by $P$. aeruginosa. (a) represents the reference standarts on TLC plates. (b) and (c) present residual TNT and its metabolits that accumulated in biotic and abiotic cultures.

In time-dependent TNT biotransformation, bacteriamediated reduction was detected to elevate with a high cell density of $P$. aeruginosa in the log phase. In control cultures without TNT, low levels of bacterial population indicated that $P$. aeruginosa can be used TNT as nutrient in building their cells. Also, in this present work was documented that the rate of TNT removal by $P$. aeruginosa declined as it entered stationary phase, which may be due to nutrient depletion and a reduction in the microbial population based on toxicity of the accumulating transformation products. These datas are in agreement with those acquired by prior researches on TNT-biodegrading ability of $P$. aeruginosa (Tope and Jamil, 2000; Oh et al., 2003; Maeda et al., 2006). Which is contrast to our investigations, in a number of earlier experiments was noted that efficient of TNT removal rised with decreasing in the bacterial growth (Tope et al., 1999).

The findings with regard to nitrite accumulation corresponded to distribution of TNT from culture medium throughout incubation. A rise in the level of recorded nitrite ions was substantially revealed by the decrease in TNT concentrations. In the light of the above findings, it was clearly a evidence that liberation nitrite by utilization TNT as a growth substrate under enrichment cultures with yeast extract. The occurence of nitrite ions manifests a release of nitrogen from the aromatic ring during degradation reaction. Besides, nitrite ions as single transformation product in abiotic cultures were identified. So, estimation of nitrite in cultures without bacteria, was verified chemical degradation correlated with decrease of TNT concentrations. Previous researchers denoted supportively our results on nitrite release by reduction during microbial processes $(\mathrm{Oh}$ et al., 2003; Litake et al., 2005; Maeda et al., 2006; Mercimek et al., 2013).

The further reduction of the released nitrite to nitrate was associated with decreasing of nitrite in all cultures during incubation time. But a distinct formation of nitrate as a result of direct oxidation of nitrite to nitrate by bacteria and chemical reactions, was not encountered. In contast to our datas, some searchers indicated the findings of nitrate in the cultures of Clavibacterium, Sphingomonas and their mixture during destruction of TNT (Rahal and Moussa, 2011).

During removal process of TNT by $P$. aeruginosa, all of the cultures except abiotic were appeared color changes. It was observed that the color of the culture mediums returned to a pinksih red to brown around 10-12 $\mathrm{h}$ of incuba- 
tion, gradually darkened and changed a deep red color for a prolonged period. In previous reports of TNT biotransformation, the hydride-Meisenheimer complex of TNT formed by aerobic microbial degradation that occured via the elimination of nitro groups, were detected to be responsible for these color changes (Kim and Song, 2000; Pak et al., 2000; Litake et al., 2005; Nyanhongo et al., 2009).

Intermadiates of TNT from red-coloured supernatant were analyzed to clarify the mechanisms by which metabolic pathway of TNT removal. The incorporated bacteria converted TNT to 2,4-DNT and 4-ADNT as well as nitrite, was determined by TLC and GC-MS analyses. The presence of two degradation products in P. aeruginosa cultures with nitrite, and in abiotic controls demonstrated that absence of 2,4-DNT and 4-ADNT, indicated that transformation TNT was biologically mediated by $P$. aeruginosa. The presence of impurities in originating from TNT was also shown by this analytical methods. This results supported to HPLC datas that indicated TNT was not completely used by $P$. aeruginosa. Formation of 2,4-DNT and 4-ADNT from TNT proves that reduction by two different biochemical routes: 1 . the elimination nitro groups to nitrite/nitrate; 2. the reduction of nitro groups to amines.

As earlier mentioned, TNT is a symmetrical nitroaromatic compound with nitro groups present on a carbon ring at the 2, 4 and 6 positions and a methyl group localate in the 1 position (Gallagher 2010). These arrangement that procured stability of aromatic ring and the electronwithdrawing properties of nitro groups surronding its aromatic ring created steric hindrance (Claus et al., 2007; Kubota et al., 2008). Due to the presence of multiple nitro groups on the aromatic ring, TNT has electron deficient in $\pi$-orbitals. The potentiality of electrophilic attack that leading to ring fission declines as the number of nitro groups on aromatic ring increases (Han 2008). So, microbial activites on TNT be limited to elimination of nitro groups from aromatic ring and metabolism of the remaining carbon skeleton (Spain 1995).

Aerobic reduction of TNT was summarized in three categories: 1. ring oxygenation that leads to accumulation of nitrite ions, 2. nucleophilic attack by the addition of a hidride ion to form a hydride-Meisenheimer complex that reduce the aromatic ring to di-nitro derivate (Kulkarni and Chaudhari, 2007) 3. partial reduction of the nitro group to a hydroxylamine derivate (Spain 1995). In case of anaerobic processes, TNT was degraded either by respiration of the $\mathrm{NO}^{2-}$ groups or by removal of the $\mathrm{NO}^{2-}$ groups to be used as a terminal electron acceptor or as a nitrogen source (Gallagher 2010). TNT was catalyzed to 2,4,6-triaminotoluene (TAT) as final product in anaerobic conditions (Hawari et al., 2000; Esteve- Núñez et al., 2001).

Upon review of the above information, in this study appearance of red color during degradation and the accumulation of 2,4-DNT, 4-ADNT and nitrite as biotransformation products, demonstrated that $P$. aeruginosa can reduce the aromatic ring to dinitro-compounds by forming hydride-Meisenheimer complex, which subsequently caused the release of nitrite. And it was described that the further reduction of the nitro groups to amino groups occured by using the nitro-group as electron acceptor in the second biochemical reeaction.

\section{Acknowledgments}

The authors would like to thank Cukurova University, Institute of Science, Scientific Research Project Unit and Mechanical and Chemical Industry Corporation, Rocket \& Explosive Factor for help.

\section{References}

Al-Absi A (2008) Nitrate contamination of ground water and methemoglobinemia in gaza strip. J Al-Aqsa Unv 12:1-14.

Alvarez MA, Kitts CL, Botsford JL et al. (1995) Pseudomonas aeruginosa strain MA01 aerobically metabolizes the aminodinitrotoluenes produced by 2,4,6-trinitrotoluene nitro group reduction. Can J Microbiol 41:984-991.

Ayoub K, Van Hullebusch ED, Cassir M et al. (2010) Application of advanced oxidation processes for TNT removal: A review. J Hazard Mater 178:10-28.

Barreto-Rodrigues M, Silva FT, Paiva TCB (2009) Characterization of wastewater from the Brazilian TNT industry. J Hazard Mater 164:385-388.

Claus H, Bausinger T, Lehmler I et al. (2007) Transformation of 2,4,6-trinitrotoluene (TNT) by Raoultella terrigena. Biodegradation 18:27-35.

Coral G, Karagoz S (2005) Isolation and characterization of phenanthrene-degrading bacteria from a petrolem refinery soil. Ann Microbiol 55:255-259.

Dodard SG, Powlowski J, Geoffrey I et al. (2004) Biotransformation of 2,4,6-trinitrotoluene (TNT) by enchytraeids (Enchytraeus albidus) in vivo and in vitro. Environ Pollut 131:263-273.

Esteve-Núñez A, Caballero A, Ramos JL (2001) Biological degradation of 2,4,6-trinitrotoluene. Microbiol Mol Biol Rev 65:335-352.

Fleischmann TJ, Walker KC, Spain JC et al. (2004) Anaerobic transformation of 2,4,6-TNT by bovine ruminal microbes. Biochem Biophys Res Commun 314:957-963.

Fu D, Zhang Y, Lv F et al. (2012) Removal of organic materials from TNT red water by Bamboo Charcoal adsorption. Chem Eng J 193-194:39-49.

Gallagher EM (2010) Anaerobic Degradation of 2,4,6- trinitrotoluene (TNT): Molecular Analysis of Active Degraders and Metabolic Pathways. Ph.D. Dissertation, Rutgers The State University of New Jersey, New Jersey, 127 pp.

Gandia-Herrero F, Lorenz A, Larson T et al. (2008) Detoxification of the explosive 2,4,6-trinitrotoluene in Arabidopsis: discovery of bifunctional $\mathrm{O}$ - and C-glucosyltransferases. Plant J 56:963-974.

Han S (2008) In Situ Bioremediation and Natural Attenuation of Dinitrotoluenes and Trinitrotoluene. Ph.D. Dissertation, Georgia Institute of Technology, Atlanta, $262 \mathrm{pp}$.

Hawari J, Beaudet S, Halasz A et al. (2000) Microbial degradation of explosives: Biotransformation vs. mineralization. Appl Microbiol Biotechnol 54:605-618. 
Ju KS, Parales RE (2010) Nitroaromatic Compounds, from Synthesis to Biodegradation. Microbiol Mol Biol Rev 74:250272.

Kalderis D, Hawthorne SB, Clifford AA et al. (2008) Interaction of soil, water and TNT during degradation of TNT on contaminated soil using subcritical water. J Hazard Mater 15:329-334.

Kim HY, Song HG (2000) Transformation of 2,4,6-trinitrotoluene by white rot fungus Irpex lacteus. Biotechnol Lett 22:969975.

Kubota A, Maeda T, Nagafuchi N et al. (2008) TNT biodegradation and production of dhydroxylaminonitrotoluene by aerobic TNT degrader Pseudomonas sp. strain TM15 in an anoxic environment. Biodegradation 19:795-805.

Kulkarni M, Chaudhari A (2007) Microbial remediation of nitro-aromatic compounds: An overview. J Environ Manage 85:496-512.

Lin HY, Yu CP, Chen ZL (2013) Aerobic and anaerobic biodegradation of TNT by newly isolated Bacillus mycoides. Ecological Engineering 52:270-277.

Litake GM, Joshi SG, Ghole VS (2005) TNT biotransformation potential of the clinical isolate of Salmonella typhimuriumpotential ecological implications. Indian J Occup Health 9:29-34.

Lotufo GR, Blackburn W, Marlborough SJ et al. (2010) Toxicity and bioaccumulation of TNT in marine fish in sediment exposures. Ecotoxicol Environ Saf 73:1720-1727.

Maeda T, Kadokami K, Ogava HI (2006) Characterization of 2,4,6-trinitrotoluene (TNT)-metabolizing bacteria isolated from TNT-polluted soils in the Yamada Green Zone, Kitakyushu, Japan. J Environ Biotechnol 6:33-39.

Mercimek HA, Dincer S, Guzeldag G et al. (2013) Aerobic biodegradation of 2,4,6-trinitrotoluene (TNT) by Bacillus cereus isolated from contaminated soil. Microb Ecol 66:512-521.

Montgomery MT, Coffin RB, Boyd TJ et al. (2013) Incorporation and mineralization of TNT and other anthropogenic organics by natural microbial assemblages from a small, tropical estuary. Environ Pollut 174:257-264.

Moshe SSB, Ronen Z, Dahan O et al. (2009) Sequential biodegradation of TNT, RDX and HMX in a mixture. Environ Pollut 157:2231-2238.

Nam SI (1997) On-site analysis of explosives in soil evaluation of thin-layer chromotography for confirmation analyte identity. Cold Regions Research and Engineering Laboratory Special Report 97-121.

Nyanhongo GS, Aichernig N, Ortner M et al. (2009) Incorporation of 2,4,6-trinitrotoluene (TNT) transforming bacteria into explosive formulations. J Hazard Mater 165:285-290.

Nyanhongo GS, Erlacher A, Schroeder M et al. (2006) Enzymatic immobilization of 2,4,6-trinitrotoluene (TNT) biodegradation products onto model humic substances. Enzyme Microb Technol 39:1197-1204.
Oh B, Shea PJ, Drijber RA et al. (2003) TNT biotransformation and detoxification by a Pseudomonas aeruginosa strain. Biodegradation 14:309-319.

Oh KH, Kim YJ (1998) Degradation of explosive 2,4,6-trinitrotoluene by s-triazine degrading bacterium isolated from contaminated soil. Bull Environ Contam Toxicol 61:702-708.

Pak JW, Knoke KL, Noguera DR et al. (2000) Transformation of 2,4,6-trinitrotoluene by purified xenobiotic reductase B from Pseudomonas fluorescens I-C. Appl Environ Microbiol 66:4742-4750.

Park C, Kim TH, Kim S et al. (2002) Biokinetic parametrer estimation for degradation of 2,4,6-Trinitrotoluene (TNT) with Pseudomonas putida KP-T201. J Biosci Bioeng 94:57-61.

Park S, Kim TH, Kim S et al. (2003) Optimization of biodegradation of 2,4,6-trinitrotoluene (TNT) by Pseudomonas putida. J Biosci Bioeng 95:567-571.

Rahal AG, Moussa LA (2011) Degradation of 2,4,6-trinitrotoluene (TNT) by soil bacteria isolated from TNT contaminated soil. Aust J Basic Appl Sci 2:8-17.

Robertson BK, Jjemba PK (2005) Enhanced bioavailability of sorbed 2,4,6-trinitrotoluene (TNT) by a bacterial consortium. Chemosphere 58:263-270.

Schackmann A, Müller R (1991) Reduction of nitroaromatic compounds by different Pseudomonas species under aerobic conditions. Appl Microbiol Biotechnol 34:809-813.

Seth-Smith HMB (2002) Microbial Degredation of RDX. Ph.D. Dissertation, University of Cambridge, England, $139 \mathrm{pp}$.

Spain JC (1995) Biodegradation of nitroaromatic compounds. Annu Rev Microbiol 49: 523-555.

Tope AM, Jamil K (2000) Isolation of TNT tolerant Pseudomonas species (strain KA) from TNT contaminated soil biotransformation of TNT. Def Sci J 151:141-145.

Tope AM, Jamil K, Baggi TR (1999) Transformation of 2,4,6trinitrotoluene (TNT) by immobilized and resting cells of Arthrobacter sp. J Hazard Subst Res 2:3-9.

Yang Q, Liang Y, Zhou T et al. (2008) TNT determination based on its degradation by immobilized HRP with electrochemical sensor. Electrochem Commun 10:1176-1179.

Wang Z, Ye Z, Zhang M et al. (2010) Degradation of 2,4,6trinitrotoluene (TNT) by immobilized microorganismbiological filter. Process Biochem 45:993-1001.

Zaripov SA, Naumova AV, Suvorova ES et al. (2004) Initial stages of 2,4,6-Trinitrotoluene transformation by microorganisms. Microbiology 73:398-403.

Zhang M, Zhao Q, Ye Z (2011) Organic pollutants removal from 2,4,6-trinitrotoluene (TNT) red water using low cost activated coke. J Environ Sci 23:1962-1969.

Zheng W, Lichwa J, D'Alessio M et al. (2009) Fate and transport of TNT, RDX, and HMX in streambed sediments: Implications for riverbank filtration. Chemosphere 76:1167-1177.

Associate Editor: Lara Durães Sette

All the content of the journal, except where otherwise noted, is licensed under a Creative Commons License CC BY-NC. 